\title{
NUMERICAL STUDY ON THE INFLUENCE OF INFILTRATION ON SWASH HYDRODYNAMICS AND SEDIMENT TRANSPORT IN THE SWASH ZONE
}

\begin{abstract}
Alejandro Hammeken ${ }^{1}$ and Richard Simons ${ }^{1}$
Infiltration and exfiltration processes have a significant influence on the hydrodynamics of the swash zone. Such processes need to be taken into account in the modelling of cross-shore sediment transport and the prediction of beach profile evolution. This paper presents a numerical study of the swash hydrodynamics using a 2D Volume-Averaged Reynolds-Averaged Navier-Stokes model, which was calibrated and validated against new experimental data. The model was used to simulate wave run-up from regular waves over permeable and impermeable fixed slopes. Swash flow velocities and water depth data were obtained from the simulations and used to estimate bed shear stresses at three different locations on the beach slope. The results show that infiltration can have opposing effects on the bed shear stress when compared to equivalent swash on an impermeable slope. During the uprush phase, stresses are directly increased due to boundary layer thinning, whereas, during the backwash phase, there is a significant reduction of flow leading to a decrease in the bed shear stresses.
\end{abstract}

Keywords: swash, infiltration, sediment transport, hydraulic conductivity, bed shear stress.

\section{INTRODUCTION}

Accretion and erosion in the swash zone are known to be influenced by infiltration into the beach and exfiltration from the water table (Fig. 1). However, there is a need to improve our understanding of the effects of beach porosity on these processes. This will lead to better modelling of the swash zone hydrodynamics and prediction of sediment transport.

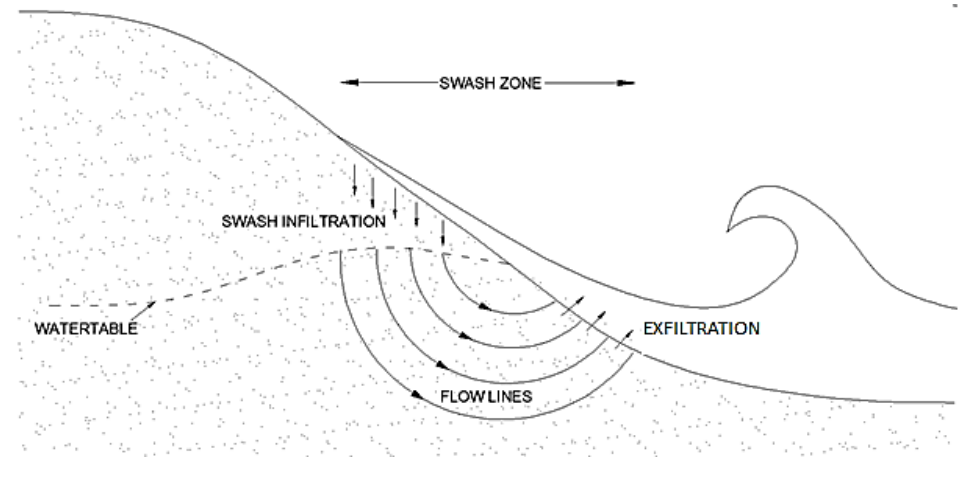

Figure 1. Infiltration and exfiltration in the swash zone (adopted from Masselink and Turner, 2012).

It is well known that infiltration influences sediment transport in the swash zone by increasing the flow asymmetry. This increase in swash asymmetry is expected to promote accretion because the energy available to carry sediment onto the beach by the uprush flow will be larger than the energy available to carry sediment away from the beach by the backwash flow. However, previous studies have reported contradictory results concerning the effects of infiltration/exfiltration on the swash zone sediment transport (e.g. Watters and Rao, 1971; Willets and Drossos, 1975; Conley and Inman, 1992; and Rao et al., 1994). Horn (2002) suggested that these contradictory results might be due to the opposing effects on the potential for sediment mobility of two additional mechanisms caused by infiltration/exfiltration: the alteration of the effective weight of the surface sediment and the modified bed shear stresses exerted on the bed due to an alteration of the boundary layer thickness.

The flow through a permeable boundary exerts a force within the bed called seepage force, which acts in the direction of the flow. During infiltration, the seepage force will tend to increase the weight of the sediment, stabilizing the bed and reducing the potential for sediment mobility. These forces will also tend to reduce the thickness of the boundary layer (thinning), which will increase the bed shear stresses, and as a consequence the potential for sediment mobility will be increased. The opposite will occur during exfiltration. According to Nielsen et al. (2001), the relative importance of these opposing effects depends on the hydraulic conductivity of the bed and the density of the sediment. However, these two mechanisms do not always have opposing effects on the potential for sediment mobility, because infiltration does more than just increase the bed shear stress by thinning the boundary layer. Infiltration can also indirectly decrease the bed shear stress by reducing the volume of water in the

\footnotetext{
${ }^{1}$ Civil, Environmental and Geomatic Engineering, Chadwick Building, University College London, Gower Street, London, WC1E 6BT, United Kingdom
} 
surface flows. Baldock and Nielsen (2009) called this mechanism the 'continuity effect'. The opposing effects of these mechanisms on the potential for swash zone sediment mobility during infiltration are summarized in Table 1. The opposite will occur during exfiltration.

\begin{tabular}{|c|c|c|c|c|}
\hline Type of flow & Process & Mechanism & Consequence & $\begin{array}{c}\text { Potential for } \\
\text { sediment mobility }\end{array}$ \\
\hline \multirow{3}{*}{ Infiltration } & \multirow{2}{*}{ seepage force } & $\begin{array}{c}\text { increase the effective } \\
\text { weight of sediment }\end{array}$ & bed stabilization & reduced \\
\hline & & $\begin{array}{c}\text { boundary layer } \\
\text { thinning }\end{array}$ & $\begin{array}{c}\text { increase of bed shear } \\
\text { stresses }\end{array}$ & increased \\
\hline & flow reduction & continuity effect & $\begin{array}{l}\text { decrease of bed shear } \\
\text { stresses }\end{array}$ & reduced \\
\hline
\end{tabular}

The relative importance of the two opposing effects of infiltration on the bed shear stresses depends on the particular flow conditions. For steady, uniform flows, infiltration has been shown to increase the bed shear stresses (Chen and Chiew, 2004; Conley and Inman, 1992; Willets and Drossos, 1975). Therefore, in steady flow conditions, the direct effect will be much larger than the continuity effect. However, it is difficult to assess which effects are dominant under the highly unsteady and depth-variant flow conditions in the swash zone, as it is challenging to measure the bottom boundary layer structure under such conditions. Although a considerable number of field studies have investigated swash flows over permeable slopes, due to their uncontrolled environment, field studies cannot offer detailed and consistent measurements inside the swash.

To overcome such limitations, recent studies have opted to use numerical models and laboratory experiments under controlled settings using non-deformable slopes to study the boundary layer dynamics in the swash zone. Most of these studies have been performed on fixed, impermeable beds, with only a few carried out on fixed, permeable slopes (e.g. Kikkert et al., 2013; Pintado-Patiño et al., 2015). These latter studies analyzed a solitary wave generated by a dam-break flow and showed that the significant reduction in backwash flows due to infiltration decreased the bed shear stresses when compared to their impermeable counterpart. This means that the continuity effect was shown to be larger than the direct effect on the backwash flows and, as a consequence, infiltration decreased the overall bed shear stresses.

Both Kikkert et al. (2013) and Pintado-Patiño et al. (2015) focused their research on a solitary wave generated by a dam-break. However, the influence of infiltration on the mechanisms that influence sediment transport requires further study for periodic waves, where infiltration can also play an important role in the swash-swash interaction. In this study, a numerical model is used to investigate how infiltration affects the swash hydrodynamics for a series of non-breaking regular waves, and, consequently, how it affects the bed shear stresses.

\section{LABORATORY EXPERIMENTS}

Wave run-up experiments were conducted in a wave-current flume, $13.7 \mathrm{~m}$ long and $0.45 \mathrm{~m}$ wide, located at University College London. These tests were used to validate the numerical model, exploring its ability to simulate the swash hydrodynamics over permeable and impermeable slopes. The flume is equipped with two piston-type wave makers capable of simultaneously acting as wave generators and as active wave absorbers. This prevents waves being re-reflected into the flume. Non-deformable impermeable and permeable $10^{\circ}$ slopes were installed inside the flume with a distance of $8.25 \mathrm{~m}$ between the wave paddle and the toe of the beach (Fig. 2).

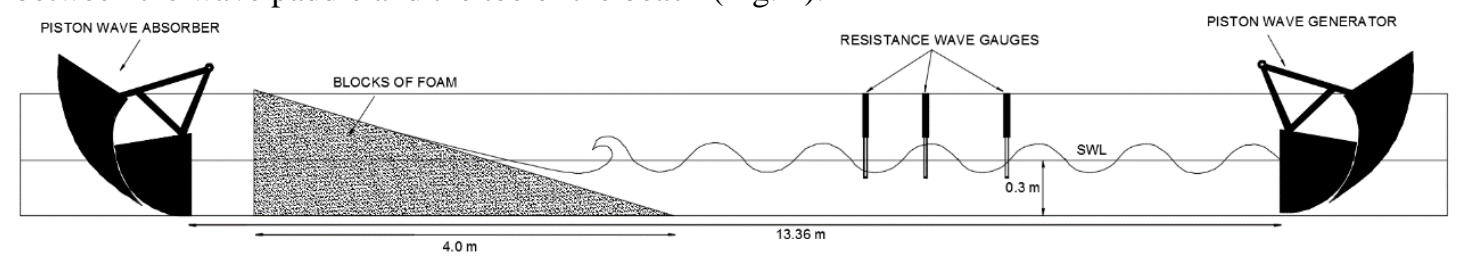

Figure 2. Experimental setup for tests with the reticulated open-cell foam beach

The impermeable slope consisted of smooth, impermeable panels held by six supports and sealed with silicon to prevent water leaking through the gaps between the walls and the slope. The permeable slope consisted of reticulated open-cell foams, which have a homogeneous cellular structure and are classified depending on their cell size or their 'pores per inch' (PPI). For these tests, a 30PPI foam was 
chosen to build the permeable beach, as its hydraulic conductivity $(K=0.401 \mathrm{~m} / \mathrm{s})$ is typical of those in coarse sand to medium gravel beaches, where the effects of infiltration on the swash hydrodynamics are more evident.

These experiments provided controlled and repeatable conditions which allowed high-resolution flow velocity and swash depth measurements at the location shown in Fig. 3. The flow velocities were taken at 30 different vertical positions from 0 to $30 \mathrm{~mm}(1000 \mathrm{~Hz}$ at $1 \mathrm{~mm}$ vertical spacing) using an LDV system. The data from 50 waves were used to derive ensemble-averaged velocities. The water depth was obtained by creating time-stack images from videos recorded from the side of the flume. To avoid bubbles and turbulence, which can affect the quality of the LDV measurements, the tests were restricted to regular non-breaking waves $(H=0.05 \mathrm{~m}$ and $T=4 \mathrm{~s})$. For a more detailed description of these laboratory experiments and measuring techniques refer to Hammeken (2017).

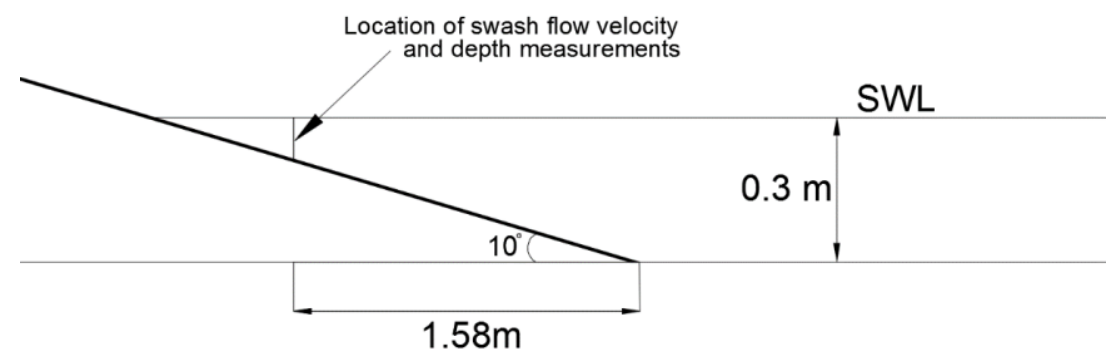

Figure 3. Location in the swash zone where the flow velocity and water depth measurements were taken

\section{NUMERICAL MODEL}

The numerical simulations in this study were performed using a Reynolds-Averaged Navier-Stokes (RANS) model. The wave transformation and breaking processes simulated by RANS models have already been validated for a large number of cases (e.g. Lara et al., 2006, 2008, 2011; TorresFreyermuth et al., 2007, 2010; Pedrozo-Acuña et al., 2010). However, due to the lack of highresolution velocity measurements inside the swash zone, less effort has been devoted to RANS model validation inside this region. In 2013, Torres-Freyermuth et al. validated the capability of a RANS model to simulate a dam break-driven swash event over impermeable slopes against the ensembleaveraged data presented by O'Donoghue et al. (2010). The model showed reliable predictions of the swash depth, flow velocities, run-up distance and bed shear stresses when compared against the laboratory measurements. More recently, Pintado-Patiño et al. (2015) further validated the RANS model's capability of predicting a dam break-driven swash event, but this time over a permeable bed. They compared the swash depth, flow velocity, run-up distance and bed shear stress measurements presented by Kikkert et al. (2013) on fixed, permeable beds against their simulated results, with their comparisons showing good agreements.

In the present study, the $I H-2 V O F$ model is used as it is capable of simulating flow through hybrid domains (outside and inside the porous media) and includes several wave generation and active wave absorption boundary conditions. In IH-2VOF, the surface flows are modelled by solving the twodimensional Reynolds-Averaged Navier-Stokes (RANS) equations, coupled with a $k$ - $\varepsilon$ turbulence closure model, while the porous media flow in IH-2VOF is modelled by solving the Volume-Averaged Reynolds-Averaged Navier-Stokes (VARANS) equations, also coupled with a $k-\varepsilon$ turbulence closure model. In the IH-2VOF model, the RANS equations are solved by the finite difference two-step projection method (Chorin, 1968, 1969) and the volume of fluid method (VOF) presented by Hirt and Nichols (1981) is used to track free-surface locations. A detailed description of the governing equations for surface and porous flows and the VOF technique used in IH-2VOF can be found in Lin and Liu (1998), Losada et al. (2008), Torres-Freyermuth et al. (2010) and Lara et al. (2011).

The VARANS equations in IH-2VOF include the extended Darcy-Forchheimer equation to account for the resistance forces created by the structure of the porous media. The extended DarcyForchheimer equation includes linear and non-linear terms to account the laminar and turbulent flows respectively, as well as an inertia term. It can be expressed as:

$$
I=a\left\langle\bar{u}_{\imath}\right\rangle+b|\langle\bar{u}\rangle|\left\langle\bar{u}_{\imath}\right\rangle+c_{A} \frac{\partial\left\langle\bar{u}_{\imath}\right\rangle}{\partial t}
$$


where " \langle\rangle " denotes the intrinsic volume averaging operator, $I$ is the hydraulic gradient, $\overline{u_{i}}$ is the ensemble-averaged flow velocity, $a$ and $b$ are the resistance coefficients, while $c_{A}$ is the added mass coefficient. The first two terms on the right hand side of (1) represent the linear and non-linear terms included to account for the laminar and turbulent flows, respectively, while the last parameter is the virtual added mass coefficient proposed by Polubarinova-Kochina (1962) given by:

$$
c_{A}=\gamma \frac{1-n}{n}
$$

where $n$ is the porosity and $\gamma$ is an empirical coefficient that is commonly assigned a value $\gamma=0.34$. Several authors have proposed formulations to determine values for the coefficients $a$ and $b$ in (1) relating them with porosity and mean nominal grain diameter, $d_{50}$. In the IH-2VOF model, the formulations used to determine these coefficients are given by:

$$
\begin{gathered}
a=\alpha \frac{(1-n)^{2}}{n^{3}} \frac{v}{d_{50}^{2}} \\
b=\beta \frac{1-n}{n^{3}} \frac{1}{d_{50}}
\end{gathered}
$$

where $v$ is the kinematic viscosity, while $\alpha$ and $\beta$ are empirical resistance coefficients. These coefficients depend on the porous media and flow characteristics, so their values need to be calibrated.

\section{Calibration of Porous Media Resistance Coefficients}

To replicate the run-up laboratory experiments carried out on the permeable foam slope, it was necessary to find appropriate values for the resistance coefficients $\alpha$ and $\beta$ needed to simulate the flow through this foam. This was done by performing steady flow tests through unconfined porous dams made of the beach material. In these tests, two bodies of water separated by a porous rectangular dam lay above an impermeable bed. A flow through the dam was established by imposing a head difference between the two bodies of water. Steady flow was achieved when the head difference became stable $(H$ and $h$ ). At this moment, the water levels of the two bodies, as well as the water table elevation or free flow surface throughout the porous dam were recorded (Fig. 4).

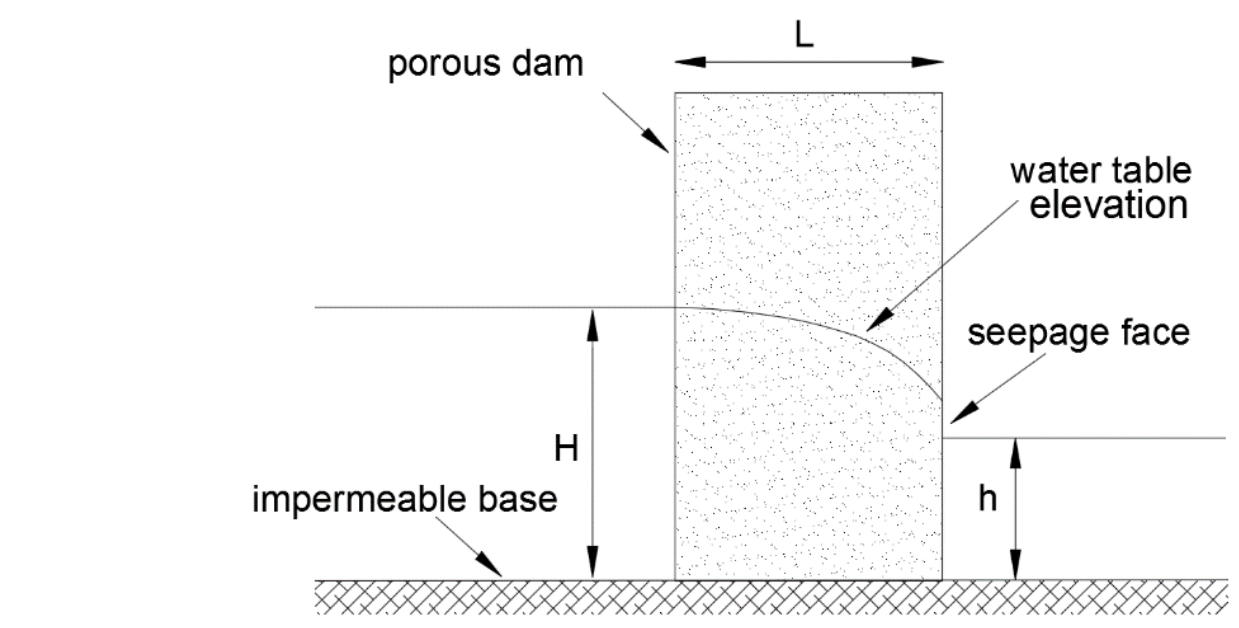

Figure 4. Sketch of steady flow through an unconfined porous dam

The calibration consisted of comparisons between measured and simulated water table elevations through the porous dams. Several simulations were run with different combinations of $\alpha$ and $\beta$ values and the coefficients from the simulations showing the best agreement with the measured data were selected for use in the run-up validation tests. A complete description of the calibration procedure and the steady flow test is described in Hammeken (2017). 
The results from the calibration shown in Table 2 gave the best agreement when compared to the experimental data and were used to validate the model.

\begin{tabular}{|c|c|c|c|c|}
\hline$d_{50}(\mathrm{~mm})$ & $n$ & $a$ & $\beta$ & $y$ \\
\hline 11.3 & 0.4 & 100 & 1 & 0.34 \\
\hline
\end{tabular}

\section{Numerical Model Setup}

The numerical model was set up to mimic the wave run-up laboratory experiments. However, to produce appropriate waves the numerical domain was set to be $30 \mathrm{~m}$ long; hence the toe of the structures was located at $22.53 \mathrm{~m}$ from the beginning of the domain. To decrease the simulation time, the domain was split into three different subzones, making it possible to reduce the overall number of cells, for both the horizontal $X$ and vertical $Y$ directions. The mesh discretization and subzones are sketched in Fig. 5. The subzone with the highest resolution was located where wave breaking and the swash processes occur ( $X$ and $Y$ subzones 2). This region consisted of a uniform mesh grid with constant horizontal $\Delta x$ and vertical $\Delta y$ cell sizes. A high resolution was also set along the free surface throughout the entire domain ( $Y$ subzone 2 ). For all other subzones outside the main areas of interest, a variable mesh grid was used to reduce the number of cells. To avoid false breaking, the aspect ratio has to be between $1<\Delta x / \Delta y<5$. For these simulations, a vertical cell size of $\Delta y=0.005 \mathrm{~m}$ and a horizontal cell size of $\Delta x=0.01 \mathrm{~m}$ were used, which resulted in an aspect ratio of $\Delta x / \Delta y=2$.

The regular waves were generated using Cnoidal wave theory and active wave absorption was used for both the inlet and outlet boundaries. The simulations were run for 200 s to derive ensembleaveraged velocities from 50 waves. These simulations were completed in approximately 9 hours for the impermeable slope, and approximately 13 hours for the permeable slope (on one processor core).

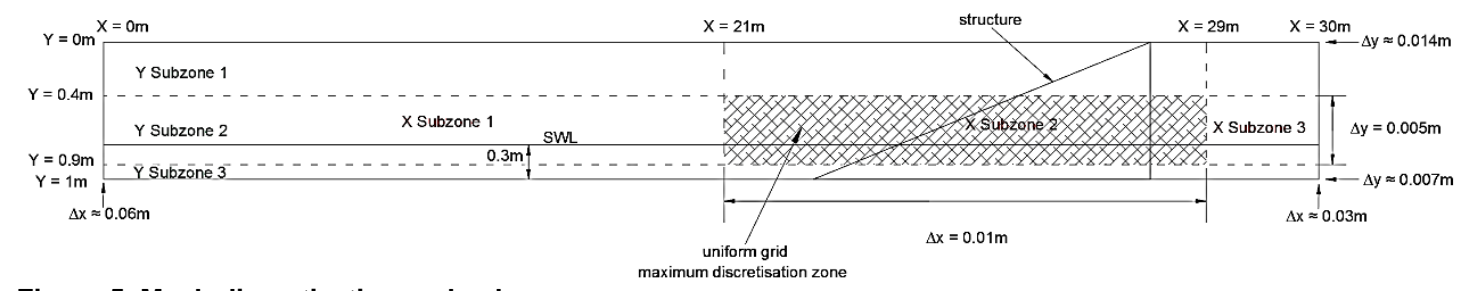

Figure 5. Mesh discretization and subzones

\section{VALIDATION OF THE NUMERICAL MODEL}

This section presents comparisons between measured and simulated swash depth and flow velocity data, obtained from the location shown in Fig. 3 on both the impermeable and permeable slopes.

\section{Swash Depths}

Fig. 6 shows the time-series of the simulated (solid line) and measured (line with markers) water depths for the impermeable and permeable foam slopes. The dashed lines indicate the $\pm 15 \%$ error bands (with respect to the measured data). In this analysis, the arrival of the bore is considered to be the initial time $(t=0 \mathrm{~s})$. For both slopes, the simulated data show good agreement through most of the swash events. Slight discrepancies are seen after flow reversal which may be attributed to the use of a video camera to measure water depths, as surface tension can slightly increase the location of the water surface projected onto the side glass wall.

The graphs show that, at this location, the model predicts the duration of the swash event accurately for both the impermeable and permeable cases. On the impermeable slope, the total swash event lasts approximately $3.15 \mathrm{~s}$ from the arrival of the bore until the end of the backwash, while, on the permeable slope, the swash duration is shorter, lasting approximately $2.75 \mathrm{~s}$.

\section{Ensemble-Averaged Horizontal Velocity Profiles}

The evolution of the simulated and measured near-bed ensemble-averaged horizontal velocity profiles on the impermeable and permeable slopes are shown in Fig. 7 and Fig. 8 respectively. These graphs show the recorded profiles at time-steps of $0.2 \mathrm{~s}$ in the region $0-30 \mathrm{~mm}$ above the bed. The dashed lines in each graph indicate the $\pm 15 \%$ error bands. 

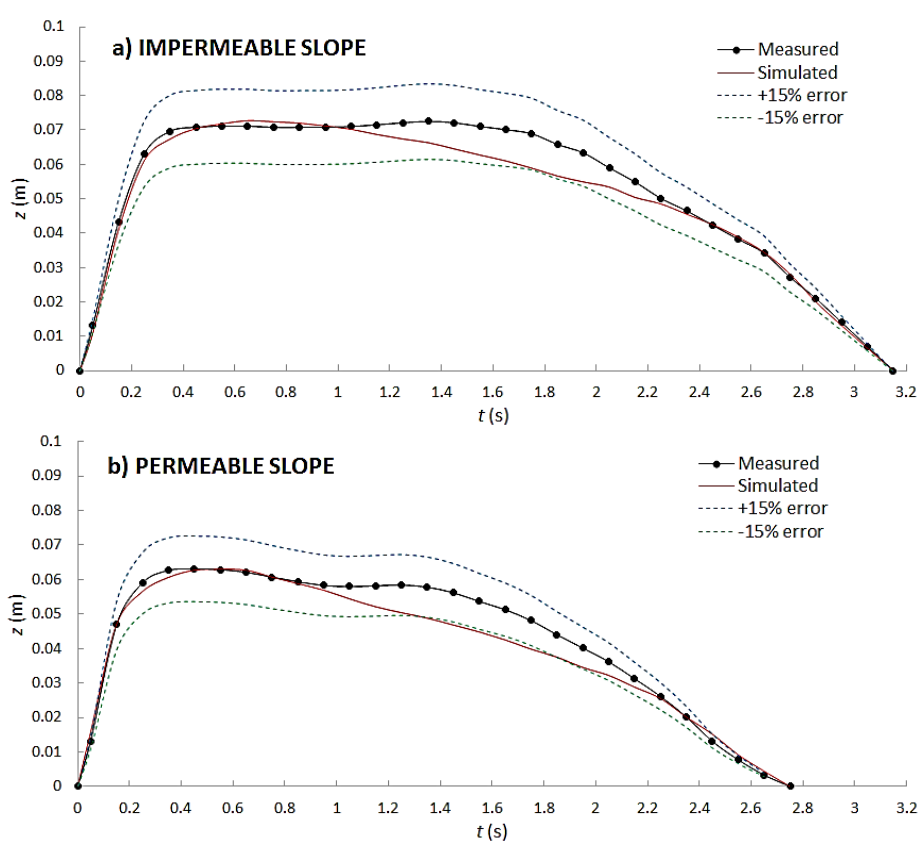

Figure 6. Comparisons between measured and simulated swash depths from a regular wave with $H=0.05 \mathrm{~m}$ and $T=4 \mathrm{~s}$. a) impermeable slope; b) permeable slope.
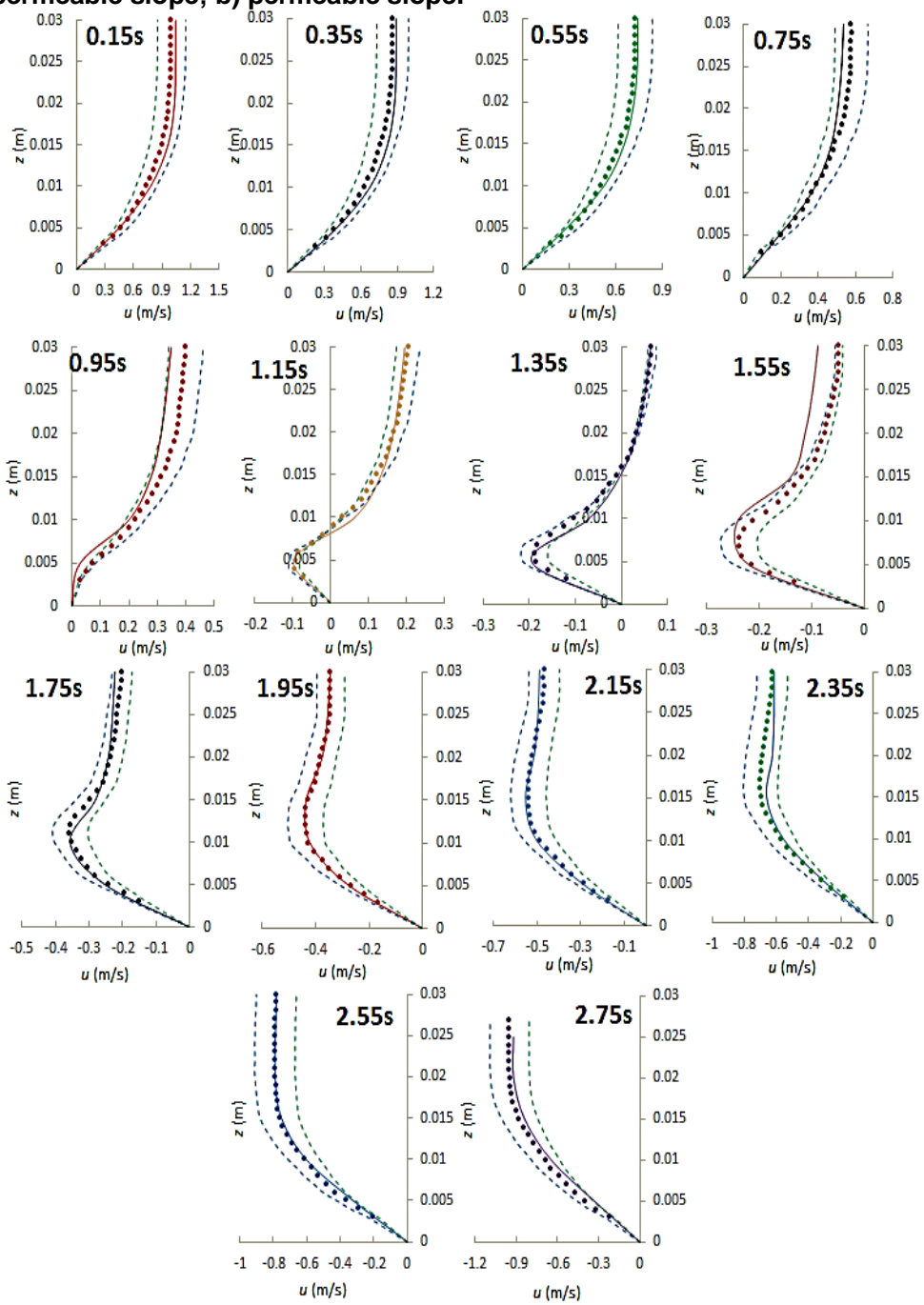

Figure 7. Comparison between measured (points) and simulated (lines) velocity profiles for the swash event on the impermeable slope at time-steps of $0.2 \mathrm{~s}$ 

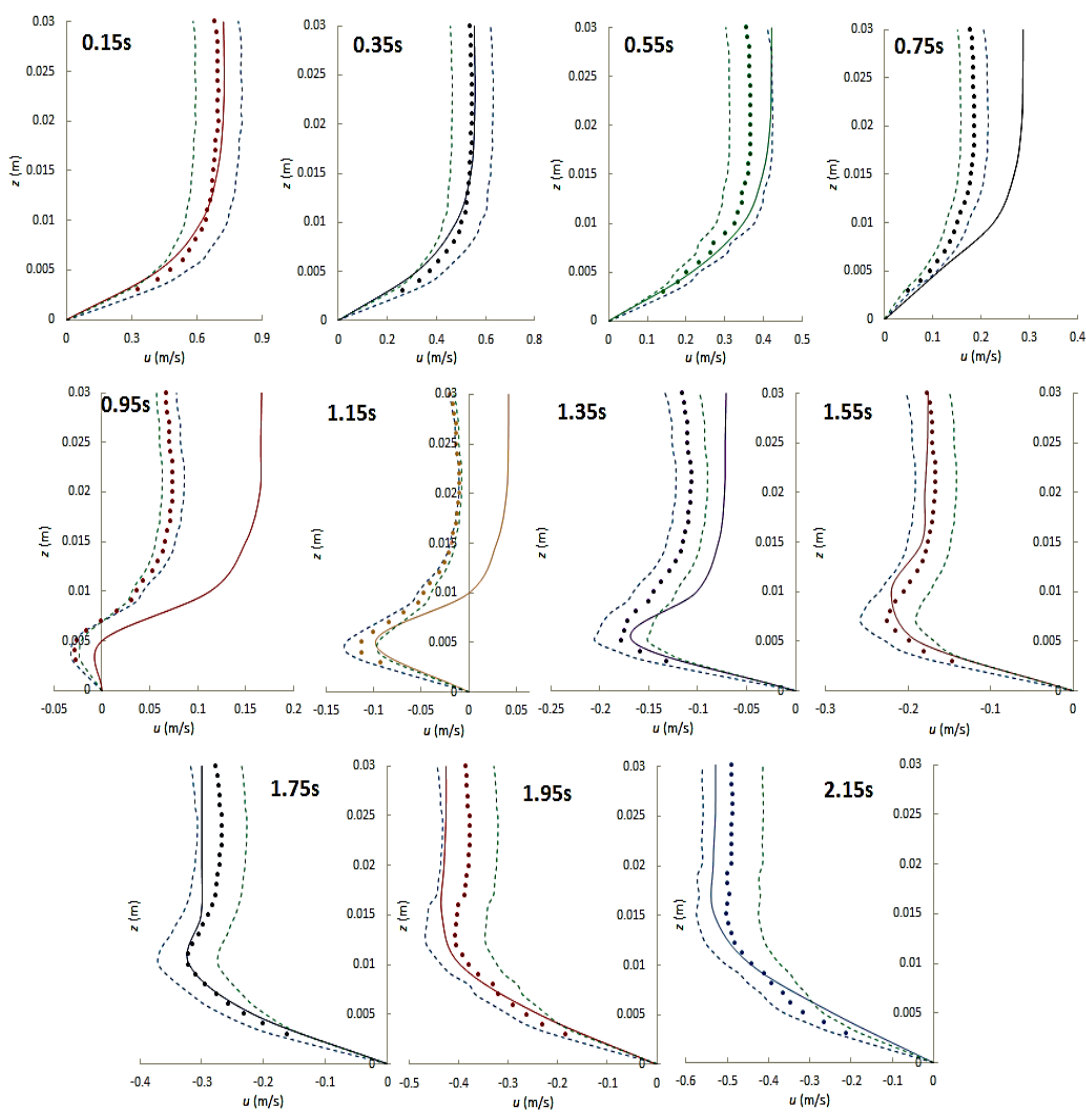

Figure 8. Comparison between measured (points) and simulated (lines) velocity profiles for the swash event on the permeable slope at time-steps of $0.2 \mathrm{~s}$

There is good agreement between most of the simulated data and the near-bed horizontal velocity measurements. Although there are some differences for the flow reversal profiles on the permeable slope (between $0.75<t<1.55 \mathrm{~s}$ ), most simulated data lie well inside the $15 \%$ error bands on both slopes. The discrepancies between the simulated and measured flow velocities might be attributed to the air phase that is not resolved by the numerical model. In a 2D model, the air bubbles can significantly affect the simulated flows, as these cannot escape laterally. Therefore, air bubbles might be trapped, or expelled into the bore, and larger turbulent kinetic energy may be induced (Lin and Liu, 1998). Another error source may be the technique used to process the experimental velocity data. As shown in the Figs.7 and 8, the LDV system can provide detailed velocity measurements of shallow swash flows. However, the raw data obtained from the LDV contained significant noise and outliers, so it was necessary to apply a smoothing method to clean and de-spike these data. The raw data contained significant outliers. Therefore, a robust local regression method was adopted to smooth the data, as it assigns lower weight to outliers in the regression. However, the use of an alternative smoothing technique would have yielded slightly different results. Nevertheless, the good agreement shown between most of the simulated and measured data validates the use of the model inside the swash zone. The model was therefore deemed appropriate for use in further investigations into the influence of infiltration on the swash hydrodynamics and bed shear stresses.

\section{RESULTS}

To investigate the influence of infiltration on the swash hydrodynamics and bed shear stresses, swash flow velocity and water depth data were obtained from the simulations at the three locations on the impermeable and permeable beach slopes shown in Fig. 9. 


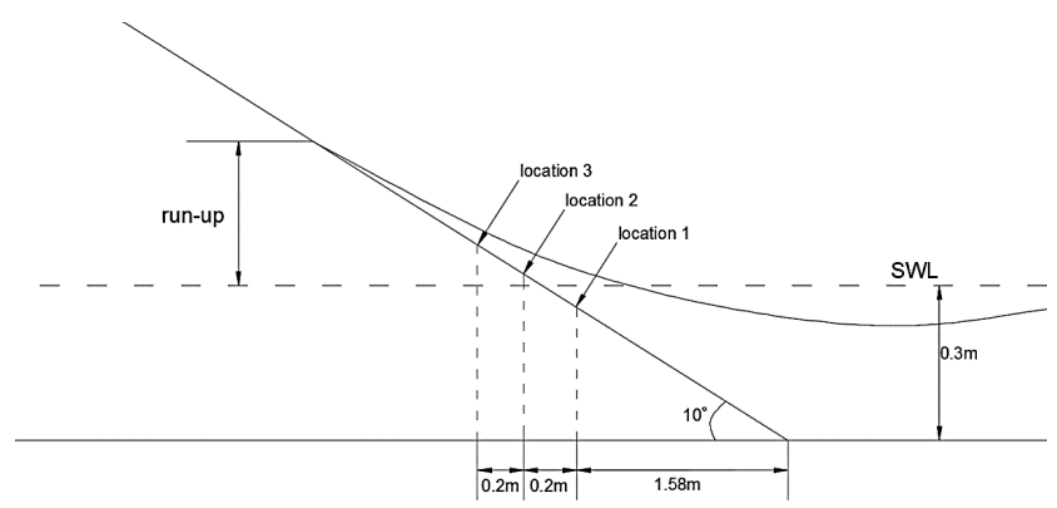

Figure 9. Swash zone locations where the velocity and water depth data were obtained

To enable comparisons between the impermeable and permeable slopes and between locations, normalized time, space and velocity coordinates are introduced in this analysis. The time dimension is normalized as:

$$
t^{\prime}=\frac{t}{t_{\text {swash }}}
$$

where $t_{\text {swash }}$ is the total duration of the swash cycle of each case, hence $t$ ' ranges from 0 to 1 . The vertical space coordinates are normalized by the maximum water depth, $h_{\max }$, of each case:

$$
h^{\prime}=\frac{h}{h_{\max }}
$$

Finally, the velocity coordinates are normalized by the maximum uprush depth-averaged ensemble-averaged horizontal velocities, $u_{u}$, of each case:

$$
u^{\prime}=\frac{u}{u_{u}}
$$

In all the graphs shown in this analysis, the arrival of the bore is considered to be the initial time, $t=0$.

\section{Swash Depths and Swash Duration}

Fig. 10 compares water depth profiles on the impermeable and permeable slopes at locations 1,2 and 3. To visualise the influence of infiltration on the swash durations, Figs. 10a, 10b and 10c plot the normalised water depths, $h$ ', against time, $t$. Similarly, the influence of infiltration on the water depths is shown Figs.10d, 10e and 10f, where the water depths, $h$, are plotted against the normalised time, $t^{\prime}$. It | can be seen that, infiltration reduces both parameters and these reductions are more evident further up the slope. The reductions in swash duration are mainly attributed to the significant decrease of the backwash periods caused by infiltration. The effects of infiltration on water depth are observed just before the bores reach their maximum water depth. These reductions remain fairly constant until the end of the backwash periods.

\section{Swash Asymmetries}

The influence of slope infiltration on the swash hydrodynamics becomes clearer when the time and velocity asymmetries $\left(T_{u} / T_{b}\right.$ and $u_{u} u_{b}$, respectively) are analyzed. These flow asymmetries on the permeable (dotted black line) and impermeable (solid black line) slopes are plotted in Fig. 11 | against the horizontal locations, $x$. The horizontal locations were previously shown in Fig. $3(x=1.58 \mathrm{~m}$ being the toe of the beach). As a reference, the red solid line indicates the value of unity for the asymmetry (where the uprush flow is equal to the backwash flow). These graphs show that infiltration enhances onshore time and velocity asymmetry. This increase in flow asymmetry, mainly attributed to the significant reduction of the backwash period, is expected to promote onshore sediment transport. 

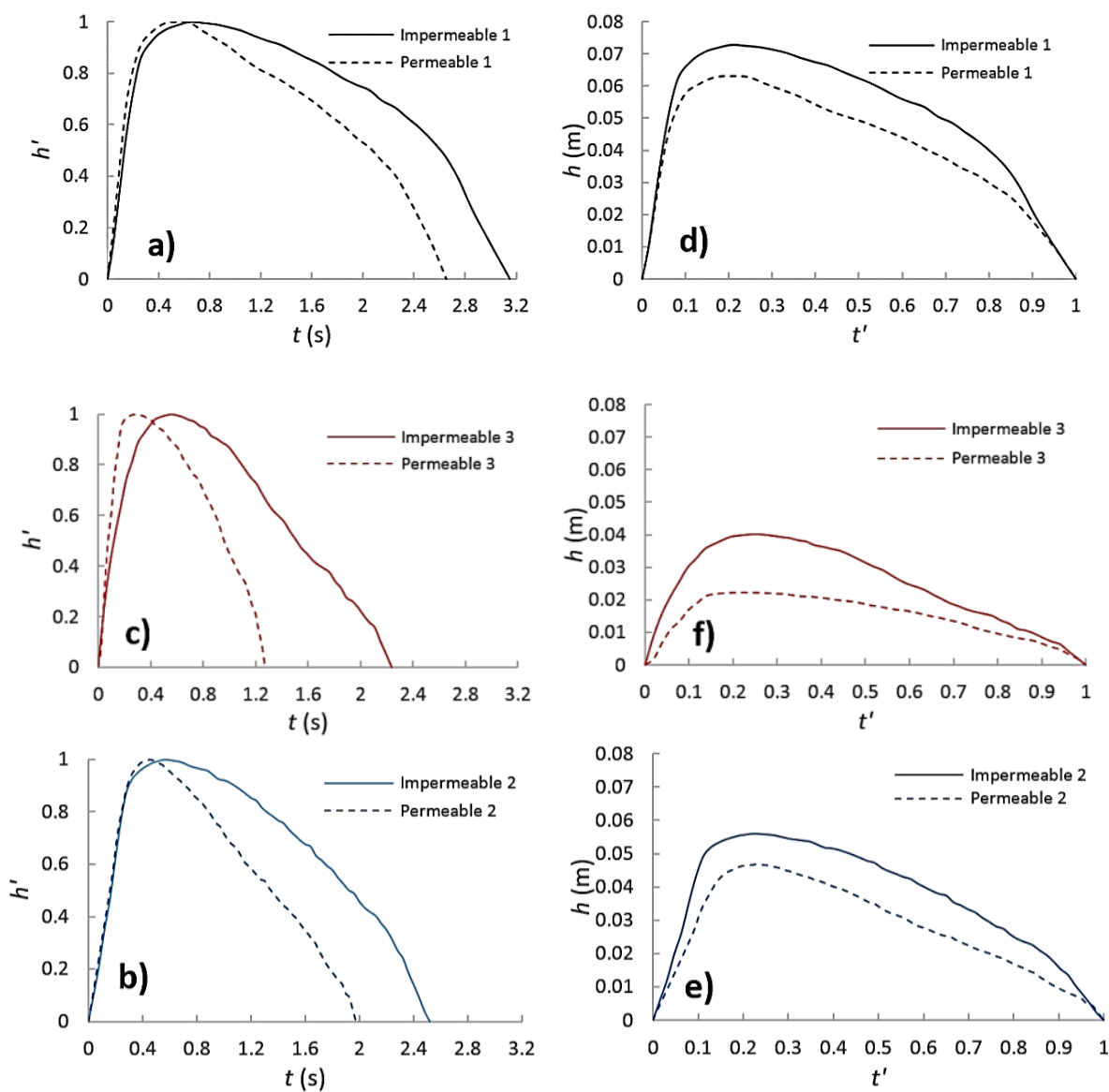

Figure 10. Comparisons of water depth profiles for impermeable (solid lines) and permeable (dashed lines) slopes at locations 1, 2 and 3. Graphs a, b and c show the normalized depth, $h^{\prime}$, against time, while graphs d, $e$ and $f$ show the depth against the normalized time, $t$ '.
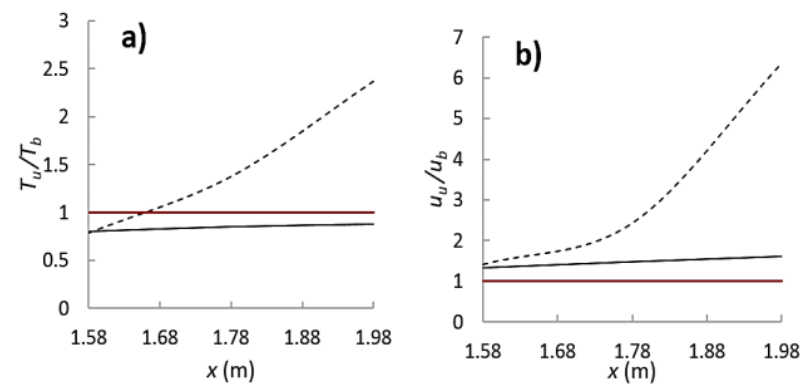

Figure 11. Swash asymmetry on permeable (dotted black lines) and impermeable (solid black line) slopes: a) Time asymmetry and b) velocity asymmetry.

Table 3 summarizes the periods of uprush, $T_{u}$, and backwash, $T_{b}$, and their corresponding time asymmetry, $T_{u} / T_{b}$, while Table 4 displays the maximum uprush, $u_{u}$, and backwash, $u_{b}$, depth-averaged ensemble-averaged velocities and their corresponding velocity asymmetry $u_{u} u_{b}$. These are shown for both slopes at the three different locations. For ease of comparison between locations, Table 3 gives the uprush and backwash periods in terms of the non-dimensional scale $t$ '.

On the impermeable slope, the uprush and backwash periods and maximum velocities have similar magnitudes at the three locations analyzed, hence, $T_{u} / T_{b}$ and $u_{u} u_{b}$ remain close to 1 (solid black lines in Fig. 11). The uprush periods are always slightly shorter than the backwash periods, and therefore, $T_{u} / T_{b}$ remains smaller than unity. Nevertheless, $T_{u} / T_{b}$ gradually increases with distance up the slope: from 0.79 at location 1 , to 0.85 at location 2 , and finally to 0.88 at location 3 . Similar results were shown by Masselink and $\mathrm{Li}$ (2001), who observed that $T_{l} / T_{b}$ increases progressively from 0.5 to 1 in the landward direction. 
Table 4 shows that the uprush velocities are always slightly larger than the backwash velocities, hence, $u_{u} u_{b}$ remains larger than 1 (Fig. $11 \mathrm{~b}$ ), and the velocity asymmetry also slightly increases with distance up the slope.

Although infiltration reduces the periods and velocities of both the uprush and backwash phases, the major differences occur on the backwash phase. The reduction in backwash flow increases with distance up the slope, and as a consequence, both $T_{u} / T_{b}$ and $u_{u} u_{b}$ also increase significantly in the landward direction (dashed lines in Fig.11). This increase in onshore flow and time asymmetry is expected to promote onshore sediment transport, as the amount of sediment carried away from the beach is reduced. This supports the claim from beach dewatering promoters that beach erosion can be reduced by lowering the beach groundwater levels, and thus increasing the infiltration rates.

\begin{tabular}{|c|c|c|c|c|}
\hline \multicolumn{5}{|c|}{ Table 3. Time asymmetry on impermeable and permeable slopes at locations 1, 2 and 3} \\
\hline & $\begin{array}{c}\text { Swash duration } \\
T_{s} \\
\end{array}$ & $\begin{array}{c}\text { Uprush duration } \\
T_{u} \\
\end{array}$ & $\begin{array}{c}\text { Backwash duration } \\
T_{b}\end{array}$ & $\begin{array}{c}\text { Time asymmetry } \\
T_{u} / T_{b} \\
\end{array}$ \\
\hline \multicolumn{5}{|c|}{ Location 1} \\
\hline Impermeable 1 & $t^{\prime}=1$ & $t^{\prime}=0.44$ & $t^{\prime}=0.56$ & 0.79 \\
\hline Permeable 1 & $t^{\prime}=1$ & $t^{\prime}=0.44$ & $t^{\prime}=0.56$ & 0.79 \\
\hline \multicolumn{5}{|c|}{ Location 2} \\
\hline Impermeable 2 & $t^{\prime}=1$ & $t^{\prime}=0.46$ & $t^{\prime}=0.54$ & 0.85 \\
\hline Permeable 2 & $t^{\prime}=1$ & $t^{\prime}=0.58$ & $t^{\prime}=0.42$ & 1.38 \\
\hline \multicolumn{5}{|c|}{ Location 3} \\
\hline Impermeable 3 & $t^{\prime}=1$ & $t^{\prime}=0.47$ & $t^{\prime}=0.53$ & 0.88 \\
\hline Permeable 3 & $t^{\prime}=1$ & $t^{\prime}=0.7$ & $t^{\prime}=0.3$ & 2.33 \\
\hline
\end{tabular}

\begin{tabular}{|c|c|c|c|}
\hline & $\begin{array}{c}\text { Maximum uprush } \\
\text { velocity } \\
\boldsymbol{u}^{+}(\mathrm{m} / \mathrm{s})\end{array}$ & $\begin{array}{c}\text { Maximum backwash } \\
\text { velocity } \\
\boldsymbol{u}^{-}(\mathrm{m} / \mathrm{s})\end{array}$ & $\begin{array}{c}\text { Maximum velocity } \\
\text { asymmetry } \\
\boldsymbol{u}^{+} / \boldsymbol{u}^{-}\end{array}$ \\
\hline \multicolumn{4}{|c|}{ Location 1} \\
\hline Impermeable 1 & 0.82 & -0.62 & 1.32 \\
\hline Permeable 1 & 0.58 & -0.41 & 1.42 \\
\hline \multicolumn{4}{|c|}{ Location 2} \\
\hline Impermeable 2 & 0.68 & -0.46 & 1.48 \\
\hline Permeable 2 & 0.51 & -0.21 & 2.47 \\
\hline \multicolumn{4}{|c|}{ Location 3} \\
\hline Impermeable 3 & 0.55 & -0.34 & 1.61 \\
\hline Permeable 3 & 0.47 & -0.074 & 6.36 \\
\hline
\end{tabular}

\section{Evolution of Horizontal Velocity Profiles}

The above comparisons show that infiltration decreases the swash depth, swash duration and flow velocity, especially at locations further up the slope. As mentioned in Kikkert et al., (2013), these bulk effects complicate the comparison of the velocity profiles on impermeable and permeable slopes at different time steps. Nevertheless, the velocity profiles of the ensemble-averaged horizontal velocities on the impermeable (Fig. 12a) and permeable slopes (Fig. 12b) at time-steps of $0.2 \mathrm{~s}$ are presented for location 1. This figure shows that the velocity profiles on both slopes have a similar evolution throughout the entire swash cycle. The profiles gradually evolve from profiles showing a typical logarithmic boundary layer at the beginning of the uprush stage, to profiles resembling the typical velocity profile of a wall jet at the beginning of flow reversal. Then, the wall jet profiles gradually evolve back to profiles showing logarithmic boundary layers at the end the backwash. Similar profile evolutions were observed at locations 2 and 3. 

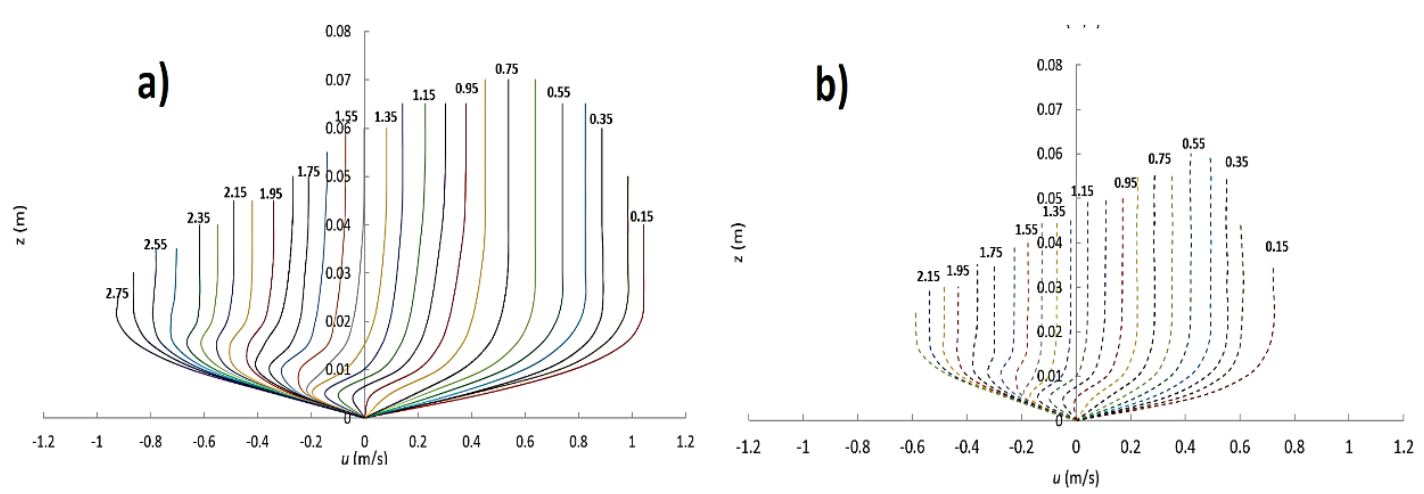

Figure 12. Evolution of horizontal velocity profiles at location 1 at every $0.1 \mathrm{~s}$ for: a) impermeable slope and b) permeable slope

\section{Boundary Layer Thickness}

In this analysis, the boundary layer thickness, $\delta$, is defined as the elevation from the bed where the velocity reaches $99 \%$ of the free stream velocity. They were obtained only from the velocity profiles that showed a logarithmic region. Fig.13 shows the evolution of $\delta$ at the three locations along both slopes during the uprush and backwash flows, where $\delta$ is plotted against the normalized time, $t^{\prime}$. At the three locations on both slopes, $\delta$ gradually increases from soon after the bore arrives until the beginning of flow reversal. After flow reversal, these gradually start to grow again until the end of the backwash phase. As discussed above, infiltration is expected to decrease $\delta$, which is seen in all three graphs. The reduction of $\delta$ caused by infiltration is similar for both the uprush and backwash flows and the scale of these changes increases further up the slope. Such changes are expected to increase the bed shear stresses exerted on the slope. However, as mentioned previously, the continuity effect of infiltration can also indirectly increase the bed shear stresses due to a loss in surface flows. This is analyzed in the following section.
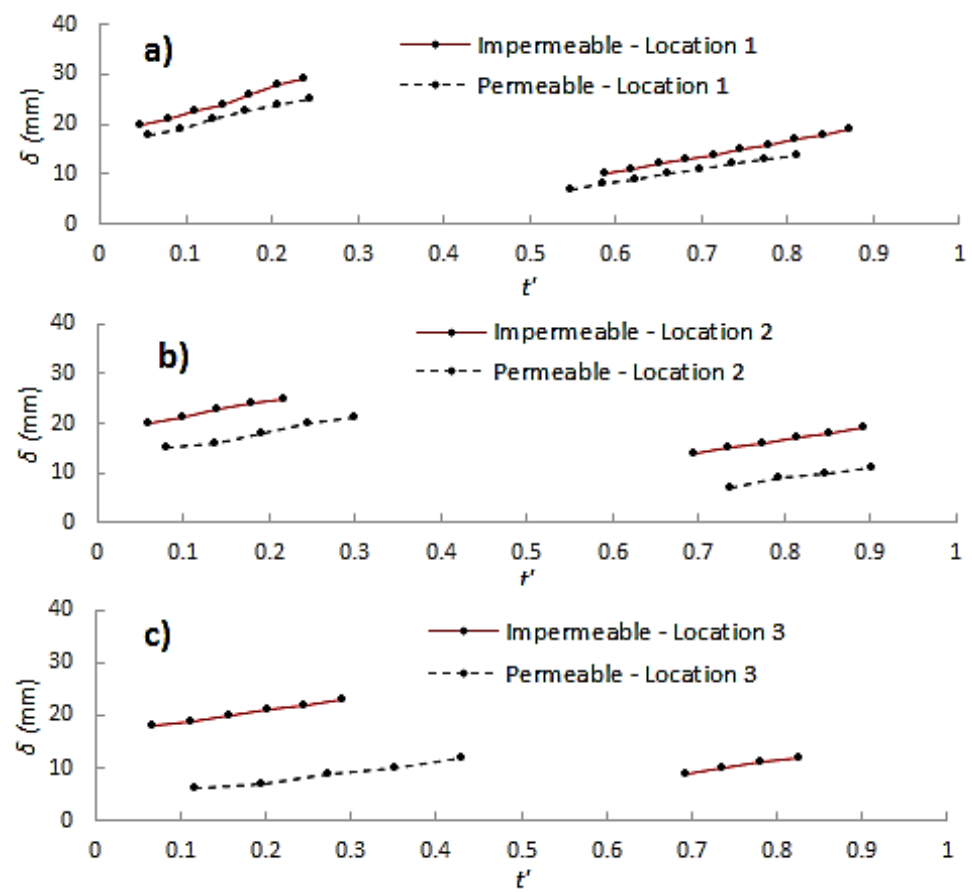

Figure 13. Boundary layer thickness on impermeable and permeable slopes at: a) location 1; b) location 2; and c) location 3.

\section{Bed Shear Stresses}

The bed shear stresses can be estimated indirectly using the near-bed velocity measurements through a number of different methods such as application of momentum balance to a control volume, logarithmic profile fitting to the measured velocity profiles (log-law method), and relating the shear velocity to the turbulent kinetic energy dissipation rate. 
Kikkert et al. (2009) evaluated the practicality of applying these methods in unsteady swash flows and showed that bed shear stress estimates based on the turbulent kinetic energy dissipation rate could only be determined when the bed shear stress values are very low (e.g. during flow reversal). Furthermore, only the momentum balance method is strictly applicable to unsteady and non-uniform swash flows. However, Kikkert et al. (2009) showed that the log-law method could also give accurate estimates of bed shear stresses in the swash zone. Their study compared estimates obtained from both the log-law and momentum balance method to estimate bed shear stresses from swash flow velocity measurements. Their estimates using the log-law showed good agreement with those obtained from the momentum balance. For this reason, the log-law method was selected in this study to estimate the bed shear stresses.

The bed shear stresses, $\tau_{0}$, on the impermeable bed were obtained using the traditional log-law method, which consists of fitting logarithmic profiles to the near bed horizontal velocity profiles. Therefore, the accuracy of this method depends on the accuracy of the velocity data. However, it cannot be applied on permeable slopes as it does not include infiltration velocities, which are known to influence the shear stresses. For permeable slopes, Chen and Chiew (2004) proposed a modified loglaw method which considers infiltration velocities and uses a similar fitting approach to the traditional log-law method, given by:

$$
\frac{u-u_{0}}{u_{*}}=\frac{1}{\kappa} \ln \left(\frac{z+z_{0}}{z_{0}}\right)+\frac{v_{0}}{4 u_{*}}\left(\frac{1}{\kappa} \ln \left(\frac{z+z_{0}}{z_{0}}\right)\right)^{2}
$$

The bed shear stresses, $\tau_{0}$, on the impermeable bed were obtained using the traditional log-law method where $u_{*}$ is the shear velocity defined as $u_{*}=\sqrt{\tau_{0} / \rho}$ ( $\rho=$ fluid density), $u_{o}$ is the horizontal velocity at the surface, $v_{o}$ is the vertical velocity at the surface (infiltration velocity), $z_{0}$ is the vertical displacement of the origin of the mean velocity profile (also called roughness length) and $\kappa$ is the von Karman constant $=0.4$. As there are several unknown values in (8), Chen and Chiew (2004) rewrote (8) as (9) to fit the data to the modified log-law and obtain the shear velocity, $u_{*}$.

$$
u=a x^{2}+b x+c
$$

where:

$$
\begin{gathered}
x=\frac{1}{\kappa} \ln \left(\frac{z+d^{\prime}}{z_{0}}\right) \\
a=\frac{v_{0}}{4} \\
b=u_{*} \\
c=u_{0}
\end{gathered}
$$

The values of $d^{\prime}, u_{*}$ and $u_{o}$ are obtained by fitting (9) to the data using a trial-and-error routine to find best fitted values. This routine consists of assigning arbitrary $d$ 'values and comparing the computed $v_{o}$ to those obtained from simulations or measurements until the error is minimized. By comparing estimates of shear velocities for sand and gravel beaches using both methods, Kikkert et al. (2013) showed that when infiltration rates are significant (e.g. gravel beach), the modified log-law gives significantly higher values than the traditional log law. As the permeable slope used in this study has a comparable hydraulic conductivity to a gravel beach, the modified log-law method was used in this analysis to compare the bed shear stresses of the impermeable and permeable slopes. These comparisons are shown in Fig. 14, where the bed shear stress estimates for both slopes at locations 1, 2 and 3 are plotted against the normalized time, $t^{\prime}$. The bed shear stresses corresponding to the flow reversal velocity profiles are not shown due to the unsuitability of the log-law on this type of profile. At location 3 of the permeable slope, none of the profiles during the backwash phase had a logarithmic region, so bed shear stresses could not be estimated for this phase. 

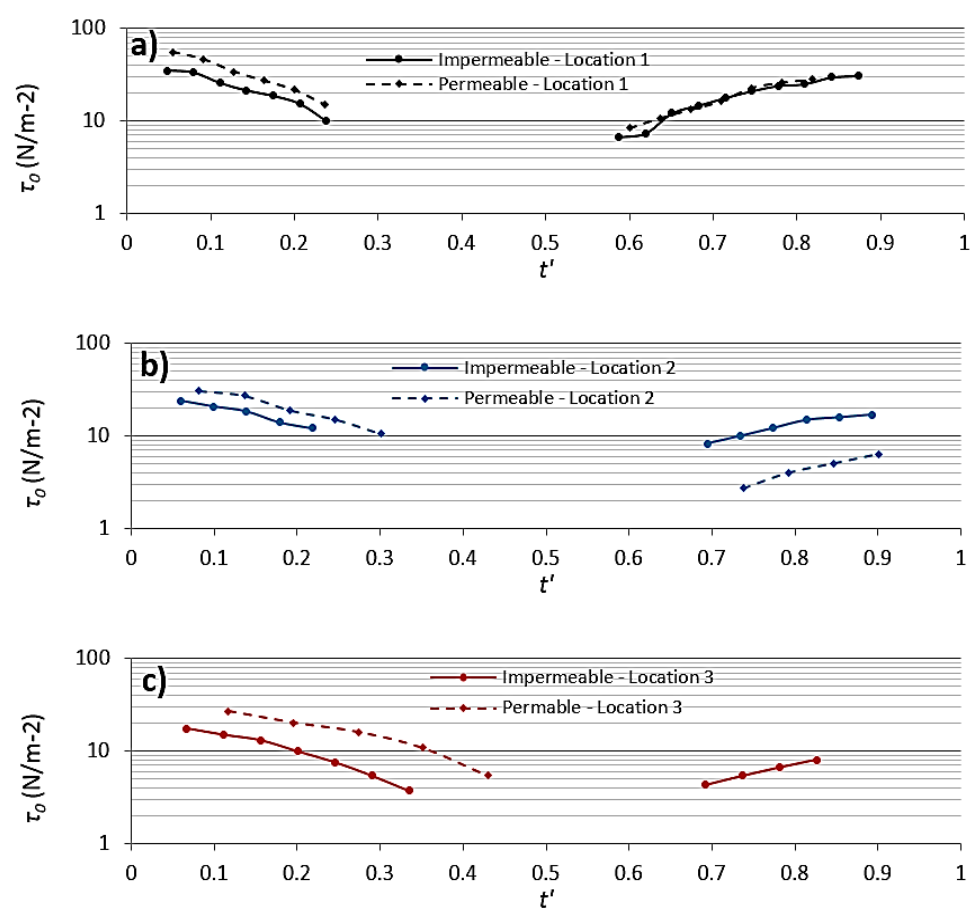

Figure 14. Bed shear stresses on impermeable and permeable slopes at location 1 (a), location 2 (b), and location 3 (c).

Fig. 14 shows that on a slope with a hydraulic conductivity of $K=0.401 \mathrm{~m} / \mathrm{s}$, infiltration can have opposing effects on the bed shear stresses. These opposing effects depend on the particular flow condition. During the uprush stages (when the flow velocities and water depths on the impermeable and permeable slopes are comparable) infiltration directly increases the bed shear stresses by thinning the boundary layer. As discussed before, this has been shown in previous studies for steady flows (e.g. Maclean, 1991; Chen and Chiew, 2004) and for oscillatory flows with suction (e.g. Conley and Inman, 1994). In contrast, the significant loss of water in the surface flow during the backwash phase results in considerably smaller flow velocities when compared to those on the impermeable slope, and consequently, the bed shear stresses are also reduced (the continuity effect). As the reductions of flow velocities and depth caused by infiltration during the backwash phase increase with distance up the slope, the reduction of bed shear stress also increases.

These results suggest that for a beach with a $K=0.401 \mathrm{~m} / \mathrm{s}$ (typical in coarse sand to medium gravel beaches), the effective weight of sediment and the bed shear stresses will have opposite effects on sediment mobility during the uprush flows, while for the backwash flows, these mechanisms will work together to decrease the potential for sediment mobility.

\section{SUMMARY AND CONCLUSIONS}

This paper has presented a numerical study on the influence of infiltration on swash hydrodynamics and bed shear stresses. The simulations were performed using a 2D VARANS model validated against laboratory run-up experiments. The porous media parameters in the model were obtained through calibration consisting of steady flow tests through porous dams. The main findings of this study are summarized below.

- Infiltration decreases the water depth, flow velocities and duration of swash events.

- These reductions increase with distance up the slope and during the backwash phases, increasing onshore time and flow asymmetry. These reductions in backwash flow are expected to reduce the sediment carried away from the beach, promoting onshore sediment transport.

- The velocity profiles on the impermeable and permeable slopes have similar evolution throughout the entire swash cycle. These show a logarithmic distribution at the beginning of the uprush phase, then gradually evolved to a wall jet type profile during flow reversal, and finally evolved back to a logarithmic profile at the end of the backwash phase.

- The log-law method was used to obtain bed shear stresses from the velocity profiles showing logarithmic distributions. The results show that infiltration directly increases the bed shear stress 
during the uprush phase by thinning the boundary layer. In contrast, the substantial reduction in backwash flow caused by infiltration indirectly reduces the overall bed shear stress when compared to the impermeable slope. This shows that modified bed shear stresses due to infiltration can have opposing effects on the potential for sediment mobility.

This study presented flow velocity and water depth data from three different locations inside the swash zone. However, the three locations do not represent the entire extent of the swash zone. Further research is still required to investigate data from the run-down to the run-up locations. Additionally, the simulations were performed on only one fixed, permeable slope, so it was not possible to quantify the influence of hydraulic conductivity on infiltration. This could be done by performing tests on several fixed, permeable slopes with constant and known hydraulic conductivities. In addition to the hydraulic conductivity, the water table elevation inside the beach can also influence the infiltration/exfiltration rates. However, as far as the authors know, this has not yet been quantified. The influence of water table elevations on the infiltration/exfiltration rates will depend on the hydraulic conductivity of the beach. Therefore, to quantify its influence, it would be necessary to carry out tests with various water table elevations on different permeable slopes with known hydraulic conductivities.

Fixed, permeable slopes with homogeneous hydraulic conductivities, such as those presented in this study, can be extremely useful for quantifying the influence of hydraulic conductivity and water table elevation on the infiltration/exfiltration processes. However, permeable beaches in nature are generally composed of mixed sediments with varying hydraulic conductivities. Therefore, further research is required to investigate infiltration/exfiltration in beaches with mixed sediments.

Understanding and quantifying these processes will improve our predictions of sediment transport in the swash zone.

\section{ACKNOWLEDGMENTS}

The authors express their gratitude to the Mexican National Council for Science and Technology (CONACYT) and UCL for the scholarships granted to Alejandro Hammeken to carry out his PhD studies.

\section{REFERENCES}

Baldock, T., \& Nielsen, P. (2009). Discussion of "Effect of Seepage-Induced Nonhydrostatic Pressure Distribution on Bed-Load Transport and Bed Morphodynamics" by Simona Francalanci, Gary Parker, and Luca Solari. Journal of Hydraulic Engineering, 136(1), 77-79.

Burcharth, H., \& Andersen, O. (1995). On the one-dimensional steady and unsteady porous flow equations. Coastal Engineering, 24, 233-257.

Chen, X., \& Chiew, Y. (2004). Velocity Distribution of Turbulent Open-Channel Flow with Bed Suction. Journal of Hydraulic Engineering, 130(2), 140-148.

Chorin, A. (1968). Numerical solution of the Navier-Stokes equations. Mathematics of Computation, $22,745-762$

Chorin, A. (1969). On the Convergence of Discrete Approximations to the Navier-Stokes Equations. Mathematics of Computation, 23(106), 341-353.

Conley, D., \& Inman, D. (1994). Ventilated Oscillatory Boundary Layers. Journal of Fluid Mechanics, 273, 261-284.

Hammeken, A. (2017). Wave Run-up on Beaches and Coastal Structures. PhD Thesis, Department of Civil, Environmental and Geomatic Engineering, University College London, UK.

Hirt, C., \& Nichols, B. (1981). Volume of fluid (VOF) method for the dynamics of free boundaries. Journal of Computational Physics, 39(1), 201-225.

Horn, D. (2002). Beach groundwater dynamics. Geomorphology, 48(1-3), 121-146.

Kikkert, G., T., Pokrajac, D., O'Donoghue, T. (2009). Bed-shear stress in bore-generated swash on steep beaches. Proceeding of the $6^{\text {th }}$ International Conference on Coastal Dynamics, 1,25.

Kikkert, G., O'Donoghue, T., Pokrajac, D., \& Dodd, N. (2012). Experimental study of bore-driven swash hydrodynamics on impermeable rough slopes. Coastal Engineering, 60, 149-166

Kikkert, G., Pokrajac, D., O'Donoghue, T., \& Steenhauer, K. (2013). Experimental study of boredriven swash hydrodynamics on permeable rough slopes. Coastal Engineering, 79, 42-56

Lara, J., Losada, I., \& Liu, P. (2006). Breaking waves over a mild gravel slope: Experimental and numerical analysis. Journal of Geophysical Research: Oceans, 111(C11), 2156-2202.

Lara, J., Losada, I., \& Guanche, R. (2008). Wave interaction with low-mound breakwaters using a RANS model. Ocean Engineering, 35(13), 1388-1400. 
Lara, J., Losada, I., Maza, M., \& Guanche, R. (2011). Breaking solitary wave evolution over a porous underwater step. Coastal Engineering, 58, 837-850.

Lin, P., \& Liu, P. (1998). A numerical study of breaking waves in the surf zone. Journal of Fluid Mechanics, 359, 239-264

Losada, I., Lara, J., Guanche, R., \& Gonzalez-Ondina, J. (2008). Numerical analysis of wave overtopping of rubble mound breakwaters. Coastal Engineering, 55(1), 47-62

Maclean, A. (1991). Open channel velocity profiles over a zone of rapid infiltration. Journal of Hydraulic Research, 29(1), 15-27

Masselink, G., \& Li, L. (2001). The role of swash infiltration in determining the beachface gradient: a numerical study. Marine Geology, 176(1-4), 139-156.

Masselink, G., \& Turner, I. (2012). Large-scale laboratory investigation into the effect of varying backbarrier lagoon water levels on gravel beach morphology and swash zone sediment transport. Coastal Engineering, 63(0), 23-38.

Nielsen, P, Robert, S., Moller-Christiansen, B., Olivia, P., (2001). Infiltration effects on sediment mobility under waves. Coastal Engineering 42, 1005-114.

O'Donoghue, T., Pokrajac, D., \& Hondebrink, L. (2010). Laboratory and numerical study of dambreakgenerated swash on impermeable slopes. Coastal Engineering, 57(5), 513-530.

Pedrozo-Acuña, A., Torres-Freyermuth, A., Zou, Q., Hsu, T., \& Reeve, D. (2010). Diagnostic investigation of impulsive pressures induced by plunging breakers impinging on gravel beaches. Coastal Engineering, 57(3), 252-266

Pintado-Patiño, J., Torres-Freyermuth, A., Puleo, J., \& Pokrajac, D. (2015). On the role of infiltration and exfiltration in swash zone boundary layer dynamics. Journal of Geophysical Research: Oceans, 120(9), 6329-6350

Polubarinova-Kochina, P. (1962). Theory of Ground Water Movement. Princeton, USA.

Rao, A.R., Subrahmannyam, V, Thayumanavan, S., Namboodiripad, D., (1994). Seepage effects on sand-bed channels. Journal of Irrigation and Drainage Engineering, 120(1), 60-79

Torres-Freyermuth, A., Losada, I., \& Lara, J. (2007). Modeling of surf zone processes on a natural beach using Reynolds-Averaged Navier-Stokes equations. Journal of Geophysical Research: Oceans, 112(C9), 2156-2202.

Torres-Freyermuth, A., Lara, J., \& Losada, I. (2010). Numerical modelling of short- and long-wave transformation on a barred beach. Coastal Engineering, 57(3), 317-330.

Watters, G.Z., \& Rao, P. (1971). Hydrodynamic effects of seepage on bed particles. Journal of the Hydraulic Division, 421-439

Willets, B.B. \& Drossos, M.E. (1975). Local erosion caused by rapid infiltration. Journal of the Hydraulic Division, 1477-1488. 